\title{
Molecular and morphological analyses of the osteogenic activity of rat cultured periosteum cells in vivo and in vitro
}

\author{
Hideki Soumiya $^{1,2}$, Kenichi Matsuzaka ${ }^{2,3}$, Takahiko Shibahara ${ }^{1}$, Takashi Inoue ${ }^{2,3}$ \\ ${ }^{\prime}$ Department of Oral and Maxillofacial Surgery, Tokyo Dental College, Chiba, Japan \\ ${ }^{2}$ Oral Health Science Center hrc7, Tokyo Dental College, Chiba, Japan \\ ${ }^{3}$ Department of Clinical Pathophysiology, Tokyo Dental College, Chiba, Japan
}

Abstract: The purpose of this study was to investigate the behavior of auto-transplanted cultured periosteum (CP) cells from rats. $\mathrm{CP}$ cells were obtained from the calvarium, and bone marrow cells were obtained from the femur. Cell proliferation rates and expression of bone-related protein mRNAs were evaluated. CP and cultured bone marrow (CBM) cells were auto-transplanted into the rectus abdominal muscle and also into the bone cavity of femurs. Immunohistochemical staining with PEBP2 $\alpha A$ was performed. Moreover, the expression of mRNAs was also analyzed. Cultured gingival fibrous (CGF) cells were used as controls. The proliferation ratio of CP was significantly higher at 3,5 and 7 days compared with CBM. Ectopic bone formation in the muscle was observed at 7 days after the $\mathrm{CP}$ transplantation. However, little bone formation was observed at 14 days in CBM transplanted areas. PEBP2 $\alpha \mathrm{A}$-positive cells in the bone cavity were observed in the CP transplanted group at day 3 and newly-formed bone was seen at 7 day. The expression of bone-related protein mRNAs of $\mathrm{CP}$ were detected earlier than in any of the other groups. $\mathrm{CP}$ has high proliferation potency and can differentiate more quickly than CBM. Thus, $\mathrm{CP}$ is the most suitable osteogenic tissue to serve as graft material.

[Oral Med Pathol 2009; 14: 19-28 doi: 10.3353/omp.14.19]

Key words: auto-transplant, bone marrow, cell culture, cell labeling, osteogenic capability, periosteum

Correspondence: Kenichi Matsuzaka, Department of Clinical Pathophysiology, Tokyo Dental College, 1-2-2 Masago, Mihama, Chiba, 261-8502, Japan

Phone: +81-43-270-3582, Fax: +81-43-270-3583, E-mail: matsuzak@tdc.ac.jp

\section{Introduction}

There have been many reports about the regeneration of bone defects using transplantation of self-organization, cross-organization or different organization, and also using artificial materials such as hydroxyapatites, $\beta$-TCP or bioactive glass (1-7). Particularly, both periosteum and bone marrow grafts, which contain many osteogenic cells, are known as suitable graft materials (8-12). The periosteum has a cambium layer, which is the osteogenic layer and which plays an important role during the wound healing of bones (13-17). Runx2 (Cbfa-1, core binding factor-1) is a runtrelated transcription factor that is essential for osteoblast differentiation. Ducy et al. reported that Cbfa-1 was used for mouse embryonal osteogenesis (18). Ueno et al. reported studies using periosteum cells obtained from tibia transplants into the suprahyoid muscles of domestic rabbits and observed the formation of cartilage (5). It is known that both mesenchymal and hematopoietic stem cells in the bone marrow are able to differentiate into bone, cartilage, muscle, blood and/or nerves depending on the environment (19-24).
Mature new bone formation has been observed when cancellous bone particulates with bone marrow were autotransplanted in humans at the cleft of the jaw (25-26). However, to obtain periosteum cells and bone marrow cells is not easy in terms of quality and quantity.

To resolve that problem, cultured osteogenic cells obtained from the periosteum and bone marrow have recently been used as graft materials (27-28). Ono et al. transplanted hydroxyapatite and cultured human bone marrow stromal cells into bone defects, and they reported that bone regeneration occurred (29). Mizuno et al. reported that cultured periosteum (CP) cells transplanted in a bone loss model due to periodontitis could be experimentally created, and they reported that bone regeneration occurred (30). Hutmacher et al. showed that $\mathrm{CP}$ from rabbits could be transplanted into partial bone defects of the tibia, and they observed bone regeneration (31). Ohya et al. reported that transplanted platelet rich plasma with particulate cancellous bone and cultured bone marrow (CBM) cells could be obtained from domestic rabbits (32). However, only the fatty marrow appeared within 3 weeks after the operation. 
Furthermore, Mahesh et al. reported that cultured human bone marrow cells could be transplanted in rat calvaria defects and they concluded that earlier bone regeneration could be seen compared with artificial material transplants (33).

Such research used only morphological observations and did not characterize the processes at the molecular level. In this study, we initially selected CP and CBM cells, evaluated them, and characterized their osteogenic capability after auto-transplantation into the femur using immunohistochemical and molecular techniques. The purpose of this study was to investigate the behavior of auto-transplanted cultures of periosteum cells from rats.

\section{Materials and methods}

\section{Experimental animals and design}

All experiments were performed according to the laboratory animal guidelines of Tokyo Dental College. In these experiments, 132 male Sprague-Dawley 4 weeks-old rats, each weighing approximately $100 \mathrm{~g}$ (Sankyo Labo Service, Tokyo, Japan) were used. Thirty rats were used for the in vitro experiments, 8 rats were used for autotransplantation of cultured cells in the rectus and 94 rats were used for the auto-transplantation of cultured cells in the cavities of femurs.

\section{Cell collection and culture}

To obtain cells, the animals were sacrificed by overdoses of thiopental sodium (Ravonal ${ }^{\circledR}$; Mitsubishi Tanabe Pharma Co, Osaka, Japan). For collection of the periosteum, the hair on the parietal region was shaved and a skin incision was made in the central region to expose the skull. The fibrous tissue of the periosteum was removed mechanically. A piece of periosteum $(10 \times 10 \mathrm{~mm})$ was obtained using a cuspis blade scalpel and was placed in $\alpha$-minimum essential medium (MEM) (Invitrogen, Gibco, Carlsbad, CA, USA) until use. The periosteum obtained was chopped into fragments approximately $2 \times 2 \mathrm{~mm}$ in size, after which they were placed with the osteogenic layer side down into $35 \mathrm{~mm}$ culture dishes for $30 \mathrm{~min}$ and then were cultured for 7 days. For culture, we used $\alpha$ - MEM containing $10 \%$ fetal bovine serum and $50 \mu \mathrm{g} / \mathrm{ml}$ gentamicin, supplemented with $10^{-8} \mathrm{M}$ dexamethasone, $10 \mathrm{mM} \beta$-glycerophosphate and $50 \mu \mathrm{g} / \mathrm{ml}$ ascorbic acid immediately before use. The culture medium was exchanged every $72 \mathrm{hrs}$.

For collection of the bone marrow, the femurs were removed. The proximal and distal ends were then resected and CBM cells were obtained from the diaphysis by flushing with the culture medium described above, using a stainless steel hypodermic needle mounted on a $2 \mathrm{ml}$ syringe. The cells were collected and centrifuged at 1,500 rpm for $5 \mathrm{~min}$, and the pellets obtained were placed in culture dishes $35 \mathrm{~mm}$ in diameter and were cultured with the medium described above for 7 days. For collection of gingival fibrous tissue, the maxillary jaw was removed. Pieces of gingiva $1.5 \times 1.5$ $\mathrm{mm}$ in size were obtained using a blade scalpel. The tissue was then chopped into pieces approximately $0.5 \times 0.5 \mathrm{~mm}$ in size, after which they were placed, fibrous tissue side down, into $35 \mathrm{~mm}$ culture dishes for $30 \mathrm{~min}$ and then were cultured for 7 days. The cells of each group were harvested with $0.25 \%$ trypsin containing $0.02 \%$ EDTA and were seeded in $75 \mathrm{~cm}^{2}$ flasks and were subcultured for 14 days and then used for the experiments. The culture medium was exchanged every $72 \mathrm{hrs}$.

\section{Cell proliferation rate assay of cultured cells}

Secondary subculture cells of each group were harvested with $0.25 \%$ trypsin and $0.02 \%$ EDTA for the cell proliferation rate assay. Approximately $5 \times 10^{3}$ cells were seeded into 35 $\mathrm{mm}$ culture dishes. The culture medium was exchanged every 72 hrs. At 3, 5, 7 and 14 days, the cells were washed with PBS, and harvested using $0.25 \%$ trypsin and $0.02 \%$ EDTA. The number of cells was measured using a ViCELL $^{\mathrm{TM}}$ Coulter Counter (Beckman Coulter, Inc, Fullerton, CA, USA). Statistics were compared using the Scheffe's test after the ANOVA one-way analysis of variance.

\section{Molecular analysis of cultured cells}

Secondary subculture cells of each group $(n=5)$ were harvested using $0.25 \%$ trypsin and $0.02 \%$ EDTA for the molecular analyses. Approximately $1 \times 10^{5}$ cells were seeded into $35 \mathrm{~mm}$ culture dishes. The culture medium was exchanged every 72 hrs. Each group of cells was analyzed by quantitative reverse transcriptase-polymerase chain reaction (qRT-RCR) assays at 3, 5 and 7 days. The cells were initially washed twice with PBS. Total RNA was then extracted from each sample using the acid guanidinum thiocyanate/phenol-chloroform method. Cultured cells at each time period were homogenized using a Bransonic (Branson Ultrasonics, Corp., Danbury, CT, USA) and were solubilized in TRIzol Reagent (Invitrogen, Carlsbad, CA, USA) and chloroform. Supernatants were obtained by centrifugation at $13,200 \mathrm{rpm}$ for $20 \mathrm{~min}$ at $4^{\circ} \mathrm{C}$, added to isopropanol, stored for at least $1 \mathrm{hr}$ at $-80^{\circ} \mathrm{C}$, and then were finally centrifuged at $13,200 \mathrm{rpm}$ for $20 \mathrm{~min}$ at $4^{\circ} \mathrm{C}$. The precipitates were obtained by decantation and were washed with $70 \%$ ethanol. The RNA pellets were dissolved in RNAase-free water, and were kept at $-20^{\circ} \mathrm{C}$ until use. Total RNA concentrations were measured by absorbance using a Nanodrop $^{\circledR}$ (ND-1000 Spectrophotometer, Thermo Fisher Scientific Inc, Waltham, MA, USA). Total RNA ( $1 \mu \mathrm{g})$ was reverse transcribed and amplified in $20 \mathrm{ul}$ using an RT-kit (QIAGEN GmbH, Hilden, Germany). cDNA synthesis was carried out using a Thermal Cycler (Thermo Fisher Scientific Inc., Waltham, MA, USA), and samples were incubated at $42^{\circ} \mathrm{C}$ for $15 \mathrm{~min}$, heated to $99^{\circ} \mathrm{C}$, and were then quick-chilled to $5^{\circ} \mathrm{C}$. qRT-PCR assays were performed using a LightCycler ${ }^{\mathrm{TM}}$ (F. Hoffman-La Roche Ltd., Basel, Switzerland). Each reaction mixture considered of $2 \mu$ l LightCycler-FastStart DNA Master SYBR Green, $0.5 \mu \mathrm{M}$ of each primer, $5 \mathrm{mM} \mathrm{MgCl} 2$ and $2 \mu \mathrm{l}$ cDNAs. Negative controls without cDNA and a standard dilution series of each cDNA template were included in each run. For analysis of real-time RT-PCR data, the second derivative maximum method was used to determine the crossing point automatically for each individual sample (Light Cycler3 date 
Table 1. Primers used for real time RT-PCR analysis

\begin{tabular}{llll}
\hline primer & \multicolumn{2}{l}{ sequence } & bp \\
\hline alkaline phosphatase & F & 5'-GGC TCT CTC CAA GAC GTA CAA C- 3' & 230 \\
& R & 3'-GCG TGG TTC ACC CGA GTG GT-5' & \\
bone sialoprotein & F & 5'-TGCGCTCCAGCTACCCAAGA-3' & 132 \\
& R & 5'-TTGGTGCTGGTGCCGTTGA- 3' & \\
osteopontin & F & 5'-CTCGGAGGAGAAGGCGCATTA- 3' & \multirow{2}{*}{207} \\
& R & 5'-CCATCGTCATCGTCGTCGTCA- 3' & \\
osteocalcin & F & 5'-GGT GCA AAG CCC AGC GAC TCT- 3' & \multirow{2}{*}{199} \\
& R & 3'-GGA AGC CAA TGT GGT CCG CTA-5' & \\
3-actin & F & 5'-CCTGTATGCCTCTGGTCGTA-3' & 220 \\
& R & 5'-CCATCTCTTGCTCGAAGTCT- 3' & \\
\hline
\end{tabular}

analysis version: 3.5.28). Data were normalized using the ratio of sample data to that of the housekeeping gene, $\beta$-actin. After normalization, mRNA levels were expressed relative to $\beta$-actin. To confirm the efficiency, melting curves were analyzed. In this experiment, the expression of alkaline-phosphatase (ALP), bone sialoprotein (BSP), osteopontin (OPN) and osteocalcin (OCN) mRNAs as markers for early osteogenesis were analyzed (Table 1).

\section{Cell collection and culture}

To obtain tissues for the in vivo experiments, the animals were anesthetized using $0.1 \mathrm{ml} / 100 \mathrm{~g}$ body weight sodium thiopental injected i.p. For collection of the periosteum, the same method described above was used. However, skin incisions of the calvaria and femurs were closed with 4-0 black silk sutures. For collection of bone marrow, a skin incision, approximately $3.0 \mathrm{~cm}$ in length, of the femoral muscle was retracted to expose the lateral aspect of the femur. A defect approximately $8.0 \times 0.8 \mathrm{~mm}$ was made in the mid-region of the lateral aspect of the femoral diaphysis, using a \#008 drill bit mounted in a slow-running dental handpiece cooled with sterilized normal saline solution. The underlying bone marrow was excised with a dental excavator, and cells were cultured exactly in the same manner as for the in vitro experiment. The muscle was sutured with 4-0 black silk and the skin was then sutured with the same size of sutures. For collection of cultured gingival fibrous cells (CGF), a mucosal incision was made in the gingiva and a piece of gingival tissue $1.5 \times 1.5 \mathrm{~mm}$ in size was obtained and cultured in the same manner as for the in vitro experiments. The collection regions were kept as open wounds. After the collection of each tissue, the animal was kept in the cage until used for the transplantation experiment. Seven days after the primary culture, the cells of each group were removed with $0.25 \%$ trypsin containing $0.02 \%$ EDTA and were seeded in $75 \mathrm{~cm}^{2}$ flasks, subcultured for 14 days and then used for the transplantation experiment. The culture medium was exchanged every 72 hours.

\section{Auto-transplants in the rectus abdominis muscle}

The subcultured cells of each group were washed 2 times with PBS before transplantation. The cells were detached using $0.25 \%$ trypsin and $0.02 \%$ EDTA, then were centrifuged and kept in culture medium at $37^{\circ} \mathrm{C}$ until use. Cell pellets of approximately $4 \times 10^{6}$ cells were used as graft materials. Animals were anesthetized using sodium thiopental. A ventral midline incision, approximately $1 \mathrm{~cm}$ in length, was made in the skin of the abdomen. Using a pair of fine scissors, a small pouch was created in the rectus abdominus muscle. The graft was then auto-transplanted in the pocket using a dental spoon excavator and the skin incision was closed with 4.0 silk sutures. The animals were sacrificed by an overdose of sodium thiopental at 7 and at 14 days. The transplanted muscles were removed and fixed in $10 \%$ neutral buffer formalin for 3 days. All specimens were washed in running water for $12 \mathrm{hrs}$ and were dehydrated with ethanol before being embedded in paraffin. Paraffin sections, approximately $5 \mu \mathrm{m}$ thick, were cut and stained with H-E. The sections were observed using a universatile photograph microscope (UPM Axiophoto 2, Carl Zeiss, Oberkochen, Germany).

\section{Auto-transplantation in the femur}

The grafting method used for the auto-transplant experiment in the femur was the same as used for the rectus abdominis muscle experiment. A skin incision, approximately $3.0 \mathrm{~cm}$ in length, was made along the lateral aspect of the left thigh, and the femoral muscles were retracted to expose the lateral aspect of the left femur. A defect approximately $8.0 \times$ $0.8 \mathrm{~mm}$ in size was created in the mid-region of the lateral aspect of the femoral diaphysis, using a \#008 dental round bar mounted in a slow-running dental handpiece cooled with sterile saline. The underlying bone marrow was excised with a dental excavator, and debris was removed by washing with phosphate buffered saline. Grafts from each group were auto-transplanted in the medullary cavity. The cavity was then covered with an e-PTFE membrane (GORE-TEX ${ }^{\circledR}, \mathrm{W}$. L. Gore \& Associates, Inc., Newark, DE, USA) to avoid extravasation of the cell-transplant and invasion of the surrounding tissue into the cavity. The muscle was sutured with 4-0 black silk and the skin was sutured with the same silk. The animals were sacrificed by an overdose of sodium thiopental at 7 and 14 days. The femurs were removed and fixed in $10 \%$ neutral buffer formalin for 3 days and then were demineralized in $10 \%$ formic acid for 3 days. All specimens were washed in running water for 12 hours and 
were then dehydrated with ethanol before being embedded in paraffin. Paraffin sections, approximately $5 \mu \mathrm{m}$ thick, were cut and stained with H-E. The sections were observed using a UPM Axiophoto (Carl Zeiss, Oberkochen, Germany).

For immunohistochemical staining, PEBP2 $\alpha$ A (Santa Cruz Biotechnology, Inc., Santa Cruz, CA, USA) was used as a primary antibody (1:1000 dilution). Endogenous peroxidase activity was blocked and the sections were soaked in $10 \%$ goat serum at room temperature for $30 \mathrm{~min}$, and then were soaked in primary antibody at room temperature for $60 \mathrm{~min}$. The specimens were then soaked in the second antibody Nichirei-Histofine simple stain MAX$\mathrm{PO}^{\circledR}$ (Nichirei Corp., Tokyo, Japan) at room temperature for 30 minutes. The sections were washed with PBS and detected using a chromogenic reaction with NichireiHistofine simple stain $\mathrm{DAB}^{\circledR}$ (Nichirei); hematoxylin was used as the counter stain. Sections were observed with a UPM Axiophoto (Zeiss).

\section{Cell labeling assay in auto-transplantation}

Cultured cells were labeled using Quantum Dot Nanocrystals Qtracker Cell Labeling kit (Invitrogen). The QdotA - B liquid was added to the culture medium of CP

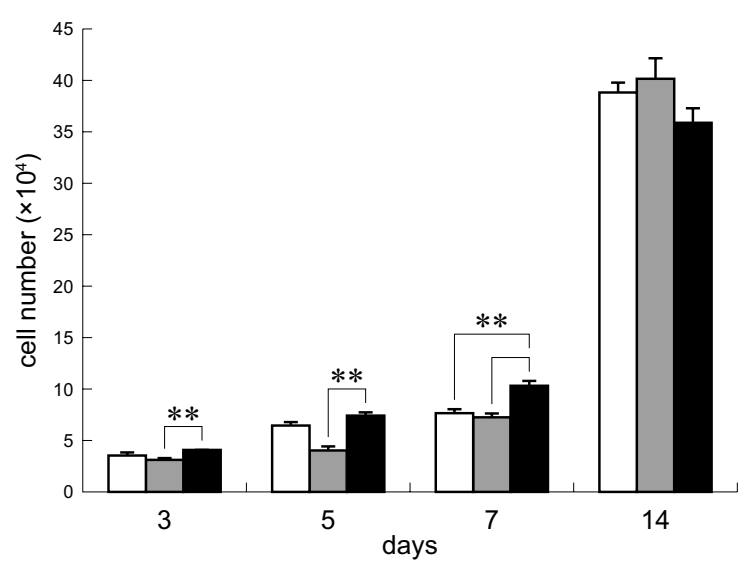

Fig. 1. Cell proliferation assay of cultured periosteum $(\mathrm{CP})$ and bone marrow $(\mathrm{CBM})$ cells and gingival fibrous $(\mathrm{CGF})$ cells. $\square$, CGF: $\square$, CBM: $\square$, CP. $(* * P<0.01)$ The proliferation ratio of $\mathrm{CP}$ was significantly higher than $\mathrm{CBM}$ at 3,5 and 7 days $(P<0.01)$. At day $7, \mathrm{CP}$ had a significantly higher cell proliferation ratio than did CGF $(P<0.01)$. No significant difference was observed among any of the groups at day 14 .

cells immediately before the transplantation. At first, $4 \mu \mathrm{l}$ Qdot A · B each liquid was added to $0.2 \mathrm{ml}$ culture solution, and then cultured for 40 minutes at room temperature. The
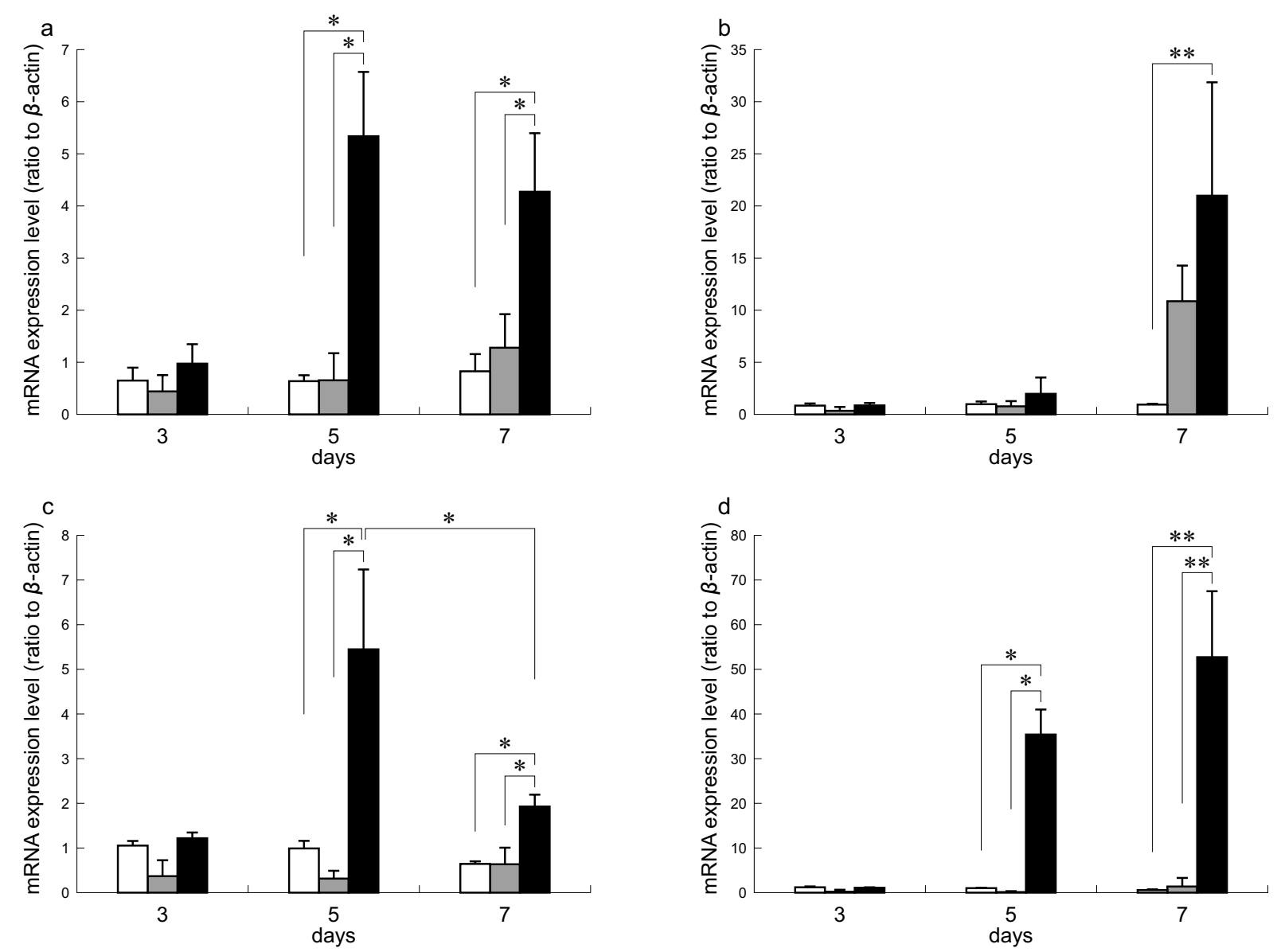

Fig. 2. mRNA expression levels of alkaline phosphatase (ALP) (a), bone sialoprotein (BSP) (b), osteopontin (OPN) (c), and osteocalcin $(\mathrm{OCN})(\mathbf{d})$ in $\mathrm{CP}, \mathrm{CBM}$, and CGF in culture. $\square$, CGF: $\square$, CBM: $\square$, CP. $\left({ }^{* *} P<0.01,{ }^{*} P<0.05\right)$ The expression of ALP mRNA by CP was highest at day 5 and was significantly higher than CBM and CGF at days 5 and $7(P<0.05)(a)$. The expression of BSP mRNA by CP was significantly higher than CGF at day $7(P<0.05)(b)$. The expression of OPN mRNA by CP was significantly higher than the other groups at days 5 and $7(P<0.05)(\mathrm{c})$. The expression of OCN mRNA by $\mathrm{CP}$ was significantly higher than the other groups at days $5(P<0.05)$ and $7(P<0.01)(\mathrm{d})$. 

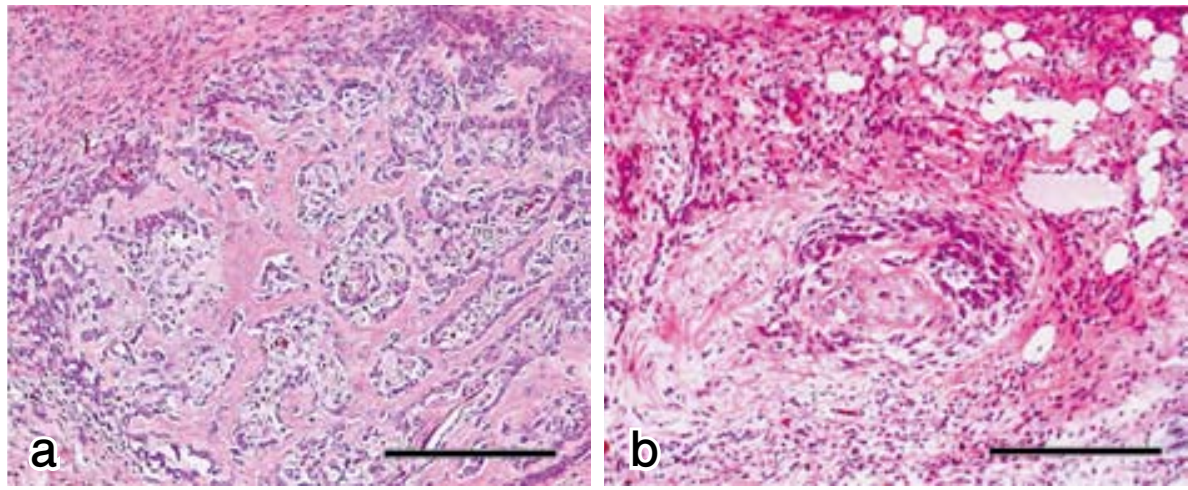

Fig. 3. Histopathology of CP, CBM and CGF cells auto-transplanted in the rat rectus abdominis muscle at day 7 (a) and day 14 (b) Hematoxylin and eosin stain, bars $=300 \mu \mathrm{m}$. Newly formed fibrous bone with numerous osteoblastlike cells was observed in the muscle where CP had been autotransplanted at day 7 (a). At day 14 , only a small amount of immature fibrous bone surrounded by mesenchymal cells was seen by $\mathrm{CBM}(\mathrm{b})$ cultured cells were auto-transplanted in the femur bone marrow cavity in the same manner as in the experimental case above. The animals were sacrificed at days 3, 5, 7 and 14 and the femurs were removed. After fixation and decalcification, paraffin sections were made according to standard methods and nuclear staining was performed using DAPI (4',6- diamino-2-phenylindole) Nucleic Acid Stain (Invitrogen, 1:300) and observed with a UPM Axiophoto (Zeiss).

\section{Molecular analysis in auto-transplantation}

Animals were sacrificed by an overdose of sodium thiopental at 3, 5,7 and 14 days after the auto-transplantation. The femurs were removed and newly formed tissues in the cavity of each femur and the expression of bone-related protein mRNAs were analyzed using qRT-PCR. The samples were kept in RNA Later ${ }^{\mathrm{TM}}$ (QIAGEN GmbH, Hilden, Germany) and then QIAzolTM (QIAGEN GmbH, Hilden, Germany) was put in a $2.0 \mathrm{ml}$ tube in $500 \mu \mathrm{l}$ and the preserved sample was added and homogenized with Tissue Lyser (QIAGEN). Total RNA was then extracted using a BIOROBOT EZ1 (QIAGEN) and an EZ1 RNA universal kit (QIAGEN). Extracted total RNA was used to produce cDNA and then was analyzed by qRT-PCR as detailed above.

\section{Results}

\section{Cell proliferation rate}

The proliferation ratio of $\mathrm{CP}$ was significantly higher than $\mathrm{CBM}$ at days 3,5 , and $7(P<0.01)$. At day $7, \mathrm{CP}$ had a significantly higher cell proliferation ratio than did CGF $(P<0.01)$. No significant difference was observed among any of the groups at day 14 (Fig. 1).

\section{Molecular analysis of cultured experiment}

The expression of ALP mRNA by CP was highest at day 5 and was significantly higher than CBM and CGF at days 5 and $7(P<0.05)$ (Fig. 2a). The expression of BSP mRNA by CP was significantly higher than CGF at day 7 $(P<0.05)$; however, there was no significant difference between $\mathrm{CP}$ and CBM at any time period examined (Fig. $2 b)$. The expression of OPN mRNA by CP was significantly higher than the other groups at days 5 and $7(P<0.05)$. The expression of OPN mRNA by $\mathrm{CP}$ at day 5 was significantly higher than at day 7 (Fig. 2c). The expression of OCN mRNA by CP was significantly higher than the other groups at days $5(P<0.05)$ and $7(P<0.01)$ (Fig. 2 d).

\section{Cultured cell auto-transplants in the rectus abdominis muscle}

Newly formed fibrous bone rimmed with numerous osteoblast-like cells was observed in the muscle where CP had been auto-transplanted at day 7 (Fig. 3a). At day 14, small bone masses with enclosed osteocytes were seen.

In the CBM auto-transplantation group, aggregation of mesenchymal cells was seen in the transplant areas at day 7; however, newly formed bone tissue was not observed. At day 14 , only a small amount of immature fibrous bone surrounded by mesenchymal cells was seen (Fig. 3b).
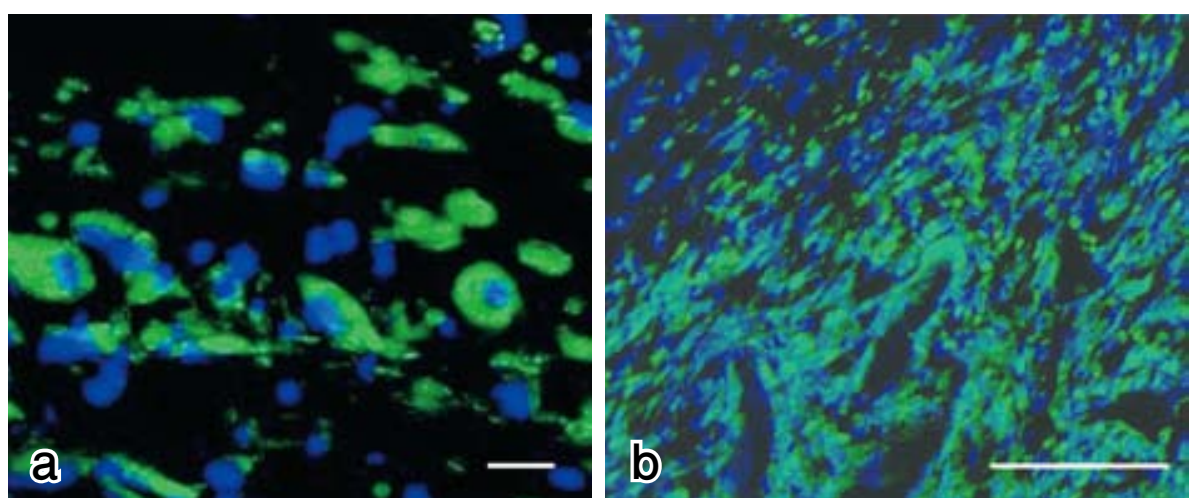

Fig. 4. Fluorescence microscopy of the rat femur bone marrow cavity labeled with nanocrystals at day 3 (a) and day 7 (b). Nanocrystals (green), 4',6-diamino-2-phenylindole (DAPI) counterstain (blue), bars $=10 \mu \mathrm{m}$ (a), $100 \mu \mathrm{m}$ (b), respectively. Nanocrystal-labeled cells were observed diffusely in the entire medullary cavity of the femur at day 3 (a). The labeling was also observed in osteoblastlike cells which were located around the newly formed bone at day 7 (b). 

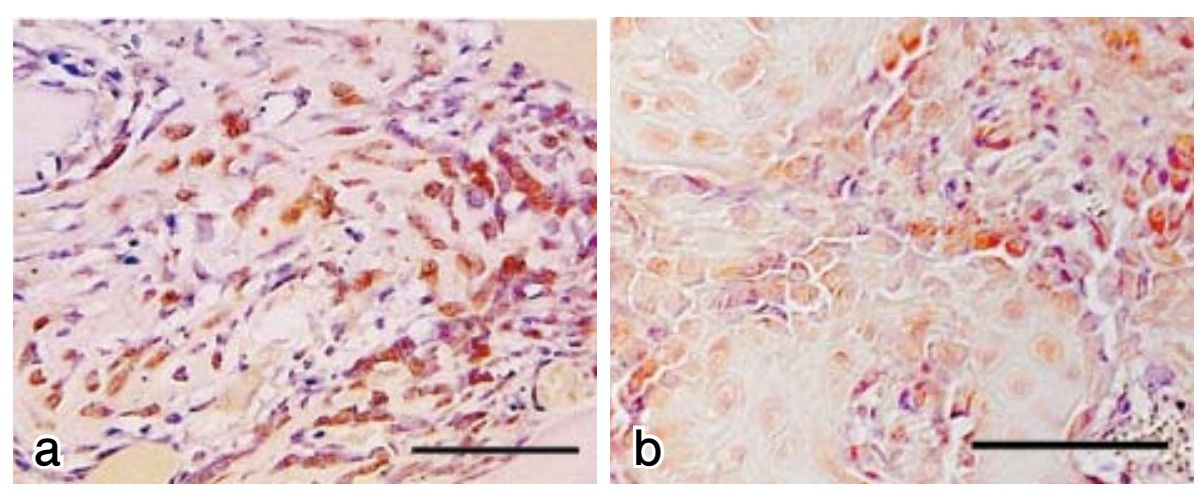

Fig. 5. Immunohistochemistry for PEBP $2 \alpha A$ in CP cells autotransplanted in rat femurs at day 7 (a) and day 14 (b). Immunoperoxidase stain, hematoxylin counter stain, bars $=100 \mu \mathrm{m}$. Many PEBP $2 \alpha A$ positive cells were observed in the entire cavity of the $\mathrm{CP}$ group, and most of the positive cells were located around the new bone (a). PEBP $2 \alpha$ A positive cells were observed not only around the new bone but also in the bone lacuna in the entire cavity of the CP group (b).

\section{Cell labeling assay of auto-plantation experiment}

Cells in which nanocrystals had been ingested were visualized green. The labeled cells were observed diffusely in the entire cavity at day 3 (Fig. 4a). At day 7, nuclear enlargement or degradation could not be seen with DAPI staining. The labeled cells were observed in spindle-shaped cells and filled the cavity. The labeled cells were also observed in osteoblast-like cells which were located around the newly-formed bone at day 7 (Fig. 4b).

\section{Cultured cells auto-transplanted in the femur bone cavity}

At day 3, each group was filled with blood clots, and cell transplants could be recognized in the center of the bone cavities; however, no blood vessels or new bone were observed. Cells slightly-positive for PEBP $2 \alpha$ A were found everywhere in the CP group, but not in either the CBM or the CGF groups. At day 5, many spindle-shaped fibroblast-like cells were observed in the cavity where $\mathrm{CP}$ had been transplanted. Blood vessels had invaded the tissue while blood clots still remained in the center of the cavities.
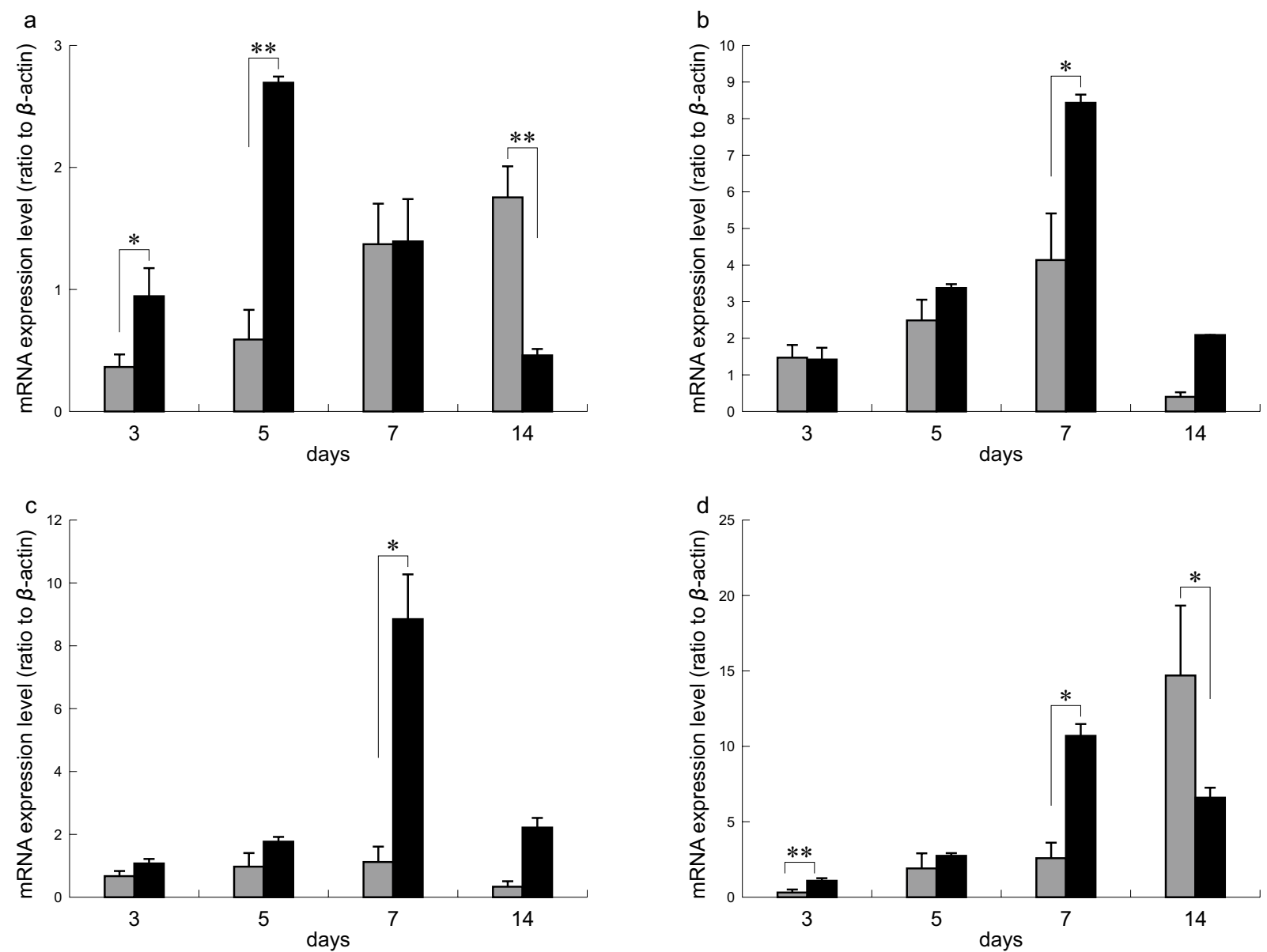

Fig. 6. mRNA expression levels of ALP (a), BSP (b), OPN (c) and OCN (d) in CP, CBM, and CGF auto-transplanted in rat femurs. CBM: $\square$, CP. $(* * P<0.01, * P<0.05)$ The expression levels of ALP mRNA by CP were significantly higher than those by $\mathrm{CBM}$ at days 3 and $5(P<0.05, P<0.01$, respectively). At day 14 , those by CBM were significantly higher those by CP $(P<0.01)$ (a). Those of BSP by CP were significantly higher than by those of CBM at day 7 ( $p<0.05)$ (b). Those of OPN mRNA by CP were significantly higher than by those CBM at day 7 and $14(P<0.05)$ (c). Those of OCN by $\mathrm{CP}$ were significantly higher than those by CBM at days 3 and at $7(P<0.05)$. At day 14, those of OCN by CBM were significantly higher than those by $\mathrm{CP}(P<0.05)(\mathrm{d})$. 
However, only transplanted cells and blood clots without invasion of blood vessels or new bone formation were observed in the cavities of both the CBM and the CGF transplanted groups. PEBP $2 \alpha$ A positive cells were observed diffusely in the entire cavity of the CP group, and a few cells were observed in the adjacent bone marrow in the cavity of the CBM group. On the other hand, blood clots still occupied the cavity of the CFG group and no PEBP $2 \alpha$ A positive cells were observed in the cavity. At day 7, the formation of new bone was first observed in the cavity of the CP group, but not in the cavities of either the CBM or the CGF groups. Many PEBP $2 \alpha A$ positive cells were observed in the entire cavity of the $\mathrm{CP}$ group and most of the positive cells were located around the new bone (Fig. 5a). PEBP $2 \alpha$ A positive cells were found in the entire cavity of the CBM group. However, there were no PEBP $2 \alpha$ A positive cells in the cavity of the CGF group. At day 14, the formation of bone with bone marrow was observed in the entire cavity of the CP group. However, only some bone formation could be observed near the margin of the cavity of the CBM group and a number of fibroblast-like cells with no bone formation were observed in the cavity of the CGF group. PEBP $2 \alpha$ A positive cells were observed in the bone and in the entire cavity of the $\mathrm{CP}$ group (Fig. 5b). PEBP2 $\alpha$ A positive cells were observed only in the cavity and strongly positive cells were observed in the margin of new bone in the cavity of the CBM group. No PEBP $2 \alpha A$ positive cells were observed in the cavity of the CGF group.

\section{Molecular analyses of the auto-plantation experiment}

The expression of ALP mRNA by CP was significantly higher than by $\mathrm{CBM}$ at days 3 and $5(P<0.05, P<0.01$, respectively). At day 14, the expression of ALP mRNA by CBM was significantly higher than by $\mathrm{CP}(P<0.01)$. The expression of BSP mRNA by $\mathrm{CP}$ was significantly higher than by $\mathrm{CBM}$ at day $7(P<0.05)$. The expression of OPN mRNA by $\mathrm{CP}$ was significantly higher than by $\mathrm{CBM}$ at days 7 and $14(P<0.05)$. The expression of OCN mRNA by CP was significantly higher than by $\mathrm{CBM}$ at days 3 and 7 $(P<0.05)$. At day 14 , the expression of OCN mRNA by CBM was significantly higher than by $\mathrm{CP}(P<0.05)$ (Fig. 6).

\section{Discussion}

Cells forming the periosteum include poorly-differentiated cells (such as osteogenic precursor cells forming the cambium layer), well-differentiated cells (such as osteoblasts), and surrounding nonspecific fibroblasts that have differentiated but retain proliferating and fibroblastic differentiation potential (13-17). Simon et al. reported that, upon collecting the periosteum, the cambium layer was divided into the bone surface and the collection surface, and many osteoblasts remained on the bone surface while many osteogenic precursor cells and fibroblasts remained on the collection surface (34). This indicates that there are many osteogenic precursor cells in cultured periosteum.

Conversely, many undifferentiated cells, such as bone marrow stem cells and hematopoietic stem cells, exist in the bone marrow (35). To examine the proliferation rates of rat $\mathrm{CBM}$ and $\mathrm{CP}$, synovial membrane and mesenchymal stem cells of fat cells, Yoshimura et al. seeded identical numbers of each type of cell after culture, and counted the number of colonies formed. They reported that in rats, cultured synovial cells showed the highest proliferation rate, followed by CP, CBM and fat cells. They also reported that although a large number of CBM cells existed within the colony, proliferation was slow because those cells gathered within the colony. Furthermore, mesenchymal stem cells that exist in soft tissues, such as the synovial membrane and the periosteum, display higher proliferating potentials (36). Choi et al. reported that in both periosteal osteogenic precursor cells and periosteal mesenchymal stem cells, stem cell markers were observed in the same manner by immunohistochemical staining, and thus these two cell populations are similar. This experiment showed the same results as those reports (37).

In the present experiment, $\mathrm{CP}$ showed a significantly higher proliferation rate compared with CBM. Furthermore, although CGF was collected from the same soft tissue, compared with CGF, CP included many precursor cells existing among the osteogenic precursor cells and in the cambium layer, and those cells were thus assumed to have a higher proliferation rate. In short, the periosteum includes many osteogenic precursor cells and is suitable for observing cell proliferation, while the periosteum is effective for obtaining sufficient numbers of cultured transplanted cells.

Numerous studies have observed the proliferation and differentiation of cells following transplantation of cultured cells. However, few investigations have tracked the dynamic state of cultured cells after labeling and transplantation. The defining feature of the nanocrystal particles used in this study is that, after incorporation into the cytoplasm, the number of particles is halved with every cell division. Jaiswal et al. reported an identification track limit for nanocrystal particles of 12 days (38). Indeed, in preliminary experiments, we found that labeled cultured CP could not be observed on day 14. The labeling experiment in our study was thus conducted for only 7 days, and DAPI and nanocrystal-positive cells were identified within the cavity on each day of the experiment. Labeled transplanted cells proliferated toward the bone marrow side of the cavity on day 3 and were spread all over the cavity on day 7 . Nanocrystals were observed in osteoblast-like cells on the new bone periphery of the cavity margin. This suggests that $\mathrm{CP}$ transplanted in this experiment is related to osteogenesis. However, cell invasion from the bone marrow clearly remained within the cavity. In this labeling experiment, the inside of the cavity was filled with labeled transplanted cells on day 7 . Within the cavity on day 7 , neoangiogenesis and invasion of osteogenic cell from the surrounding bone marrow were recognized, and many cells were nanocrystalpositive. This suggests that the extent of cell invasion from existing bone marrow is small. Accordingly, transplanted cells could be considered as related to the bone tissues observed within the cavity, and the labeling procedure used was thus shown to be valuable. 
$\mathrm{CP}$ and CBM cells were transplanted into the rectus abdominis muscle, which as a non-bone tissue does not normally form hard tissue, and osteogenesis was confirmed in this experiment. This demonstrates that $\mathrm{CP}$ and $\mathrm{CBM}$ each display an osteogenic potential. Furthermore, osteogenesis was recognized on day 7 in the CP group and on day 14 in the $\mathrm{CBM}$ group. This suggests that $\mathrm{CP}$ is able both to proliferate and to differentiate more quickly than CBM. In addition, a positive reaction for PEBP $2 \alpha A$ was seen on day 3. PEBP $2 \alpha \mathrm{A}$ is a bone transcription factor that is expressed during differentiation of osteogenic precursor cells to preosteoblast cells, at each stage of the differentiation from preosteoblast cells to osteoblasts and from osteoblasts into bone cells, and thus serves as an index of cell differentiation (18, 39-40). As PEBP2 $\alpha$ A-positive cells were observed early in $\mathrm{CP}$ in this experiment, osteogenic precursor cells are considered to exist in periosteum.

Agata et al. reported that, as a result of allotransplantation of human $\mathrm{CP}$ and CBM under mouse skin, compared with $\mathrm{CP}$, slightly higher levels of osteogenesis were recognized where the CBM cells were transplanted, which contradicts our results. However, they also reported that osteogenesis occurred early in the $\mathrm{CP}$ due to the presence of growth factors (41). Wakitani et al. reported that during the healing of wounds within bone cavities experimentally formed in the femurs of domestic rabbits, cell differentiation was promoted by the invasion of growth factors and blood vessels from the surrounding tissue (35). In our autogenous transplantation experiment within the rectus abdominis muscle, osteogenesis is thus considered to occur early for $\mathrm{CP}$ due to differences in the surrounding revascularization environment. In other words, the transplant site is the rectus abdominis muscle, which has a large number of blood vessels compared with areas under the skin. This area is thus easy to supply with nutrients, and osteogenesis occurs early in $\mathrm{CP}$.

In this study, as with the index of differentiation, the expressions of bone-related proteins, such as ALP, BSP, OPN and OCN, were analyzed by measuring mRNA levels (18, 40,42-43). Expression of mRNAs encoding OPN and OCN were recognized early in CP compared with CBM, and cultured cells and cultured cells within the cavity in the autogenous transplantation experiment showed a high osteogenic potential from a molecular perspective. Park et al. compared the expression of ALP mRNA in CP and CBM (44), while Zheng et al. studied the expression of OCN mRNA in CP (45). Since bone-related protein mRNAs were expressed early in both studies, the authors reported that $\mathrm{CP}$ display high osteogenic potential. Consistent with those findings, in the present study bone-related protein mRNAs were expressed early in $\mathrm{CP}$ because many undifferentiated cells were similarly included in the periosteum and the bone marrow in vivo and in vitro studies. Since O'Driscoll et al. reported that many osteogenic precursor cells exist in the periosteum, many osteogenic precursor cells, which display proliferative potential and for which differentiation direction had been determined, are contained in the periosteum (15). That is to say, CP exhibits a higher osteogenic potential than does CBM, even if cultured, and osteogenic potential is also maintained in the cavity, so osteogenesis occurs early in CP. $\mathrm{CBM}$ also expresses bone related protein mRNA. Expression of bone-related protein mRNA in CBM is later than that in CP.

These findings indicate that CP shows a higher proliferative potential than $\mathrm{CBM}$, and contains a larger number of bone-precursor cells that differentiate into osseous system cells. The results of this study indicate that $\mathrm{CP}$ has a higher proliferative potential and an early differentiation potential compared to CBM, and can thus be considered a highly valuable graft material.

\section{Acknowledgments}

We would like to thank Miss Saori Takano and members of the Department of Clinical Pathophysiology at Tokyo Dental College for their technical assistance. This research was supported by an Oral Health Science Center Grant hrc7 from Tokyo Dental College, and by a High-Tech Research Center Project for Private Universities Matching Fund Subsidy from the Ministry of Education, Culture, Sports, Science and Technology, Japan, for 2006-2010 and 2007-2010 (no. 19592414).

\section{References}

1. Leach JK, Kaigler D, Wang Z, Krebsbach PH, Mooney DJ. Coating of VEGF-releasing scaffolds with bioactive glass for angiogenesis and bone regeneration. Biomaterials 2006; 27: 3249-55.

2. Neo M, Herbst H, Voigt CF, Gross UM. Temporal and spatial patterns of osteoblast activation following implantation of beta-TCP particles into bone. J Biomed Mater Res 1998; 39: 71-6.

3. Ripamonti U. The morphogenesis of bone in replicas of porous hydroxyapatite obtained from conversion of calcium carbonate exoskeletons of coral. J Bone Joint Surg Am 1991; 73: 692-703.

4. Shiratori K, Matsuzaka K, Koike Y, Murakami S, Shimono $\mathrm{M}$, Inoue T. Bone formation in beta-tricalcium phosphatefilled bone defects of the rat femur: morphometric analysis and expression of bone related protein mRNA. Biomed Res 2005; 26: 51-9.

5. Ueno T, Kagawa T, Mizukawa N, Nakamura H, Sugahara T, Yamamoto T. Cellular origin of endochondral ossification from grafted periosteum. Anat Rec 2001; 264: 348-57.

6. Watanabe K, Tsuchiya H, Sakurakichi K, Tomit K. Bone transport using hydroxyapatite loaded with bone morphogenetic protein in rabbits. J Bone Joint Surg Br 2007; 89: 1122-9.

7. Yoshida K, Bessho K, Fujimura K, Konishi Y, Kusumoto K, Ogawa Y, Iizuka T. Enhancement by recombinant human bone morphogenetic protein- 2 of bone formation by means of porous hydroxyapatite in mandibular bone defects. $J$ Dent Res 1999; 78: 1505-10.

8. Nakahara H, Bruder SP, Goldberg VM, Caplan AI. In vivo osteochondrogenic potential of cultured cells derived from the periosteum. Clin Orthop Relat Res 1990; 259: 223-32.

9. Ritsilä V, Alhopuro V. Spinal fusion with free periosteal 
grafts and its effect on vertebral growth in young rabbits. $J$ Bone Joint Surg Br 1975; 57: 500-5.

10. Skoog T. The use of periosteal flaps in the repair of clefts of the primary palate. Cleft Palate J 1965; 2: 332-9.

11. Uddstromer L, Ritsila V. Osteogenic capacity of periosteal grafts. A qualitative and quantitative study of membranous and tubular bone periosteum in young rabbits. Scand. $J$ Plast Reconstr Surg 1978; 12: 207-14.

12. van den Wildenberg FA, Goris RJ, Tutein NoltheniusPuylaertMB.Freerevascularised periosteum transplantation: an experimental study. Br J Plast Surg 1984; 37: 226-35.

13. Boyne PJ. Use of Marrow-Cancellous Bone Grafts in Maxillary Alveolar and Palatal Clefts. J Dent Res 1974; 53: 821-4.

14. Muramatsu K, Bishop AT. Cell repopulation in vascularized bone grafts. J Orthop Res 2002; 20: 772-8.

15. O'Driscoll SW, Fitzsimmons JS. The role of periosteum in cartilage repair. Clin Orthop Relat Res 2001; 391: 190-207.

16. Redlich A, Perka C, Schultz O, Spitzer R, Häupl T, Burmester GR, Sittinger M. Bone engineering on the basis of periosteal cells cultured in polymer fleeces. J Mater Sci Mater Med 1999; 10: 767-72.

17. Yoo JU, Johnstone B. The role of osteochondral progenitor cells in fracture repair. Clin Ortho Relat Res 1998; 355: 73-81.

18. Ducy P. Cbfa1: a molecular switch in osteoblast biology. Dev Dyn 2000; 219: 461-71.

19. Gurevitch O, Kurkalli BG, Prigozhina T, Kasir J, Gaft A, Slavin S. Reconstruction of Cartilage, Bone, and Hematopoietic Microenvironment with Demineralized Bone Matrix and Bone Marrow Cells. Stem Cells 2003; 21: 588-97.

20. Jaquiéry C, Schaeren S, Farhadi J, Mainil-Varlet P, Kunz C, Zeilhofer HF, Heberer M, Martin I. In vitro osteogenic differentiation and in vivo bone-forming capacity of human isogenic jaw periosteal cells and bone marrow stromal cells. Ann Surg 2005; 242: 859-68.

21. Jiang Y, Henderson D, Blackstad M, Chen A, Miller RF, Verfaillie CM. Neuroectodermal differentiation from mouse multipotent adult progenitor cells. Proc Natl Acad Sci U S A 2003; 100: 11854-60; 2003.

22. Seto T, Kono K, Morimoto K, Inoue Y, Shintaku H, Hattori $\mathrm{H}$, Matsuoka O, Yamano T, Tanaka A. Brain magnetic resonance imaging in 23 patients with mucopoly saccharidoses and the effect of bone marrow transplantation. Ann Neurol 2001; 50: 79-92.

23. Toma C, Pittenger MF, Cahill KS, Byrne BJ, Kessler PD. Human mesenchymal stem cells differentiate to a cardiomyocyte phenotype in the adult murine heart. Circulation 2002; 105: 93-8.

24. Zhu SJ, Choi BH, Jung JH, Lee SH, Huh JY, You TM, Lee $\mathrm{HJ}$, Li J. A comparative histologic analysis of tissueengineered bone using platelet-rich plasma and plateletenriched fibrin glue. Oral Surg Oral Med Oral Pathol Oral Radiol Endod 2006; 102: 175-9.

25. Iino M, Ishii H, Sato J, Seto K. Histological evaluation of autogenous iliac particulate cancellous bone and marrow grafted to alveolar clefts--a preliminary report of five young adult cases. Cleft Palate Craniofac J 2000; 37: 55-60.
26. Ishii M, Ishii Y, Moriyama T, Gunji A, Morita K, Imaizumi F, Enomoto S. Simultaneous cortex bone plate graft with particulate marrow and cancellous bone for reliable closure of palatal fistulae associated with cleft deformities. Cleft Palate Craniofac J 2002; 39: 364-9.

27. Sakata Y, Ueno T, Kagawa T, Kanou M, Fujii T, Yamachika E, Sugahara T. Osteogenic potential of cultured human periosteum-derived cells - a pilot study of human cell transplantation into a rat calvarial defect model. $J$ Craniomaxillofac Surg 2006; 34: 461-5.

28. Turhani D, Watzinger E, Weissenbock M, Cvikl B, Thurnher D, Wittwer G, Yerit K, Ewers R. Analysis of cellseeded 3-dimensional bone constructs manufactured in vitro with hydroxyapatite granules obtained from red algae. J Oral Maxillofac Surg 2005; 63: 673-81.

29. Ono M, Kubota S, Fujisawa T, Sonoyama W, Kawaki H, Akiyama K, Shimono K, Oshima M, Nishida T, Yoshida Y, Suzuki K, Takigawa M, Kuboki T. Promotion of hydroxyapatite-associated, stem cell-based bone regeneration by CCN2. Cell Transplant 2008; 17: 231-40.

30. Mizuno H, Hata K, Kojima K, Bonassar LJ, Vacanti CA, Ueda M. A novel approach to regenerating periodontal tissue by grafting autologous cultured periosteum. Tissue Eng 2006; 12: 1227-35.

31. Hutmacher DW. Sittinger M. Periosteal cells in bone tissue engineering. Tissue Eng 2003; 9: 45-64.

32. Ohya M, Yamada Y, Ozawa R, Ito K, Takahashi M, Ueda M. Sinus floor elevation applied tissue-engineered bone. Comparative study between mesenchymal stem cells/ platelet-rich plasma (PRP) and autogenous bone with PRP complexes in rabbits. Clin Oral Implants Res 2005; 16: 622-9.

33. Mankani MH, Krebsbach PH, Satomura K, Kuznetsov SA, Hoyt R, Robey PG. Pedicled bone flap formation using transplanted bone marrow stromal cells. Arch Surg 2001; 136: $263-70$.

34. Simon TM, Van Sickle DC, Kunishima DH, Jackson DW. Cambium cell stimulation from surgical release of the periosteum. J Orthop Res 2003; 21: 470-80.

35. Wakitani S, Goto T, Pineda SJ, Young RG, Mansour JM, Caplan AI, Goldberg VM. Mesenchymal cell-based repair of large, full-thickness defects of articular cartilage. J Bone Joint Surg Am 1994; 76: 579-92.

36. Yoshimura H, Muneta T, Nimura A, Yokoyama A, Koga H, Sekiya I. Comparison of rat mesenchymal stem cells derived from bone marrow, synovium, periosteum, adipose tissue, and muscle. Cell Tissue Res 2007; 327: 449-62.

37. Choi YS, Noh SE, Lim SM, Lee CW, Kim CS, Im MW, Lee MH, Kim DI. Multipotency and growth characteristic of periosteum-derived progenitor cells for chondrogenic, osteogenic, and adipogenic differentiation. Biotechnol Lett 2008; 30: 593-601.

38. Jaiswal JK, Mattoussi H, Mauro JM, Simon SM. Long-term multiple color imaging of live cells using quantum dot bioconjugates. Nat Biotechnol 2003; 21: 47-51.

39. Ducy P, Zhang R, Geoffroy V, Ridall AL, Karsenty G. Osf2/ Cbfa1: a transcriptional activator of osteoblast differentiation. Cell 1997; 89: 677-80.

40. Hanai J, Chen LF, Kanno T, Ohtani-Fujita N, Kim WY, Guo WH, Imamura T, Ishidou Y, Fukuchi M, Shi MJ, Stavnezer 
J, Kawabata M, Miyazono K, Ito Y. Interaction and functional cooperation of PEBP2/CBF with Smads. Synergistic induction of the immunoglobulin germline Calpha promoter. J Biol Chem 1999; 274: 31577-82.

41. Agata H, Asahina I, Yamazaki Y, Uchida M, Shinohara Y, Honda MJ, Kagamin H, Ueda M. Effective bone engineering with periosteum-derived cells. J Dent Res 2007; 86: 79-83.

42. Nishimura R, Hata K, Harris SE, Ikeda F, Yoneda T. Corebinding factor alpha 1 (Cbfa1) induces osteoblastic differentiation of $\mathrm{C} 2 \mathrm{C} 12$ cells without interactions with Smad1 and Smad5. Bone 2002; 31: 303-12.
43. Satomura K, Krebsbach P, Bianco P, Gehron Robey P. Osteogenic imprinting upstream of marrow stromal cell differentiation. J Cell Biochem 2000; 78: 391-403.

44. Park J, Gelse K, Frank S, von der Mark K, Aigner T, Schneider H. Transgene-activated mesenchymal cells for articular cartilage repair: a comparison of primary bone marrow-, perichondrium/periosteum- and fat-derived cells. J Gene Med 2006; 8: 112-25.

45. Zheng YX, Ringe J, Liang Z, Loch A, Chen L, Sittinger M. Osteogenic potential of human periosteum-derived progenitor cells in PLGA scaffold using allogeneic serum. $J$ Zhejiang Univ Sci B 2006; 7: 817-24. 